\title{
A TRADUÇÃO COMO MEDIAÇÃO CULTURAL: ANTOLOGIA DE CONTOS DE ESCRITORAS BRASILEIRAS CONTEMPORÂNEAS EM ALEMÃO
}

\author{
Rosvitha Friesen Blume \\ Universidade Federal de Santa Catarina \\ blume@cce.ufsc.br
}

Maria Hummitzsch

Universidade de Leipzig

maharia@gmx.de

\begin{abstract}
Resumo: O presente artigo comenta a tradução de uma antologia de contos de autoras brasileiras contemporâneas para o alemão por uma equipe de três tradutoras alemãs e de uma brasileira, sob o enfoque da mediação cultural. Partindo do conceito de contexto (David Katan, 1999) como o conjunto de informações subjacentes compartilhadas pelo autor e os leitores de uma determinada área cultural, a tradução é vista como um processo de recontextualização (Juliane House, 2002). Vários exemplos desse processo, tanto do nível macro-textual quanto do nível micro-textual da antologia em questão, são discutidos aqui.
\end{abstract}

Palavras-chave: Contos de escritoras brasileiras contemporâneas em tradução, tradução para o alemão, gênero e tradução, mediação cultural.

\begin{abstract}
This article discusses the translation of an anthology of short stories of female contemporary Brazilian writers into German by a team of translators (three German and one Brazilian), under the focus of cultural mediation. Based on the concept of context (David Katan, 1999), as a set of underlying information shared by the author and readers of a given cultural field, translation is seen as a process of recontextualization (Juliane House, 2002). Several examples of this process, in both macro-
\end{abstract}


text and micro-text levels of the anthology in question, are discussed here. Keywords: Short stories of female contemporary Brazilian writers in translation, translation into German, gender and translation, cultural mediation.

\section{A tradução como mediação cultural}

Após o assim denominado cultural turn nos Estudos da Tradução, é lugar comum afirmar que a tradução excede em muito uma operação de ordem linguística. Nas palavras de Bassnett/Lefevere (1990: 8), "neither the word, nor the text, but the culture becomes the operational 'unit' of translation". O processo tradutório constitui-se, pois, muito mais numa mediação entre culturas do que numa transposição linguística.

Para David Katan, o tradutor figura como mediador, sendo a natureza dessa tarefa a seguinte: "translation for a mediator is not only about language or texts; it is a way to improve understanding between mutually non-comprehending groups." (Katan, 1999: 420) Para explicitar a natureza dessa não compreensão, Katan aplica os conceitos de texto e contexto do antropólogo E.T. Hall. O texto seria aquilo que é dito ou transmitido, enquanto o contexto seria o conjunto de informações subjacentes ao texto que podem ser presumidas como comuns ao autor e ao leitor. Normalmente ambos, texto e contexto, seriam inferidos um a partir do outro. Porém, essa inferência só poderia acontecer num ambiente cognitivo compartilhado pelo autor e o leitor, ou seja, dentro de uma mesma cultura, ou de um ambiente cognitivo compartilhado (Katan 1999: 410).

Concepção semelhante de contexto é apresentada na tese de Helena Tanqueiro (2002), onde desenvolve o que ela chama de "conceito operacional de marca cultural"

sob o conceito de "marca cultural" entendemos todas as denominações ou expressões ou referências presentes num 
texto literário a analisar cujo valor conotativo e/ou carga afectiva (no macro-contexto da obra literária e no microcontexto do segmento em que aparecem) são entendidas e partilhadas, de forma implícita, pelo autor apenas com os integrantes da área cultural a que se dirige a obra e que estão vetadas ou provocam associações diferentes aos integrantes da área cultural a que vai dirigida a tradução. (Tanqueiro, 2002: 127)

Voltando à teoria de Katan, no encontro entre culturas diferentes o contexto estaria perdido, e é ali que se faria necessária a função do mediador.

Uma cultura, por sua vez, seria composta por uma infinidade de contextos interrelacionados, desde aqueles mais próximos e acessíveis ao leitor, até os mais distantes dele, e que poderiam ultrapassar os limites de seu "mental map of the world". (Katan, 1999: 411) Os contextos serviriam como moldes ou estruturas básicas e teriam a seguinte função: "a framework of interpretation will always be necessary when interpreting a text as we do not have direct access to what is signified". (Katan, 1999: 411)

Citando Goodenough, Juliane House destaca essa função modeladora da cultura:

Culture is not a material phenomenon; it does not consist of things, people, behavior, or emotions. It is rather an organization of these things. It is the forms of things that people have in mind, their model of perceiving, relating, and otherwise interpreting them. (Goodenough apud House, 2002: 94)

House, que parte de uma abordagem análoga à de Katan em seu modelo funcional de tradução, fala, pois, da tradução "as a crosslinguistic cultural practice involving recontextualization" (House, 2002: 97, grifo nosso). 
Resumindo, pois, a função do tradutor como mediador, Katan (1999: 423) afirma: "Their task is to find a pattern of words which will extend the reader's map of world to take cognizance (...) of the source text' world."

É evidente que esta função só pode ser plenamente realizada por um tradutor que, mais do que bilíngue, seja bicultural, conforme enfatiza, entre outros, Snell-Hornby. (1988: 42) Katan fala da necessidade de o mediador ter a flexibilidade de transitar entre as duas culturas ao traduzir; isto é, ele deve ter a capacidade de observar, por um lado, o meio cultural do autor, e por outro o dos leitores do texto de partida e o dos leitores do texto de chegada, posicionandose num lugar que Katan (1999: 419-29) denomina "third position", de onde ele poderia manipular o texto, levando em consideração todas as partes: o texto de partida, o skopos, o leitor do texto de chegada e até mesmo os seus próprios objetivos como mediador. (1999: 420) Katan não detalha estes objetivos, porém consideramos que se trata das estratégias tradutórias que o tradutor / mediador se propõe a utilizar a partir de sua interpretação do texto de partida e tendo em vista certo público alvo. Seriam estes objetivos, portanto, o seu "projeto de tradução"

\section{O projeto de tradução de contos de escritoras brasileiras contemporâneas para 0 alemão}

Na prática tradutória a identificação do contexto nem sempre é fácil para tradutores, já que esta habilidade se adquire preferencialmente numa vivência direta na cultura do texto de partida, privilégio esse que muitos tradutores não têm. Por outro lado, tradutores que têm conhecimento amplo de uma determinada cultura por viverem nela e que gostariam de traduzir textos para uma língua estrangeira que dominam, encontram dificuldades no processo tradutório por lhes faltar a vivência imediata na língua / cultura do texto de chegada. O presente artigo comenta um projeto de 
tradução que proporcionou uma troca dessas vivências. Uniu-se a vivência cultural de uma nativa da língua de partida e a vivência linguístico-cultural de falantes nativas da língua de chegada.

A tradução dos contos integrantes da antologia em questão deuse no contexto de um trabalho conjunto entre mim como professora orientadora e três alunas da Universidade de Leipzig, após um curso de tradução literária que ofereci naquela instituição em 2006 . Na ocasião propusemos um projeto conjunto de elaboração, tradução e publicação de uma antologia de contos de escritoras brasileiras contemporâneas na Alemanha².

A experiência foi muito enriquecedora para ambos os lados, pelo fato de os contos selecionados por mim e traduzidos pelas alunas haverem sido amplamente discutidos em termos de sua interpretação e de suas opções tradutórias; em um intenso contato via e-mail pude oferecer ajuda especialmente na identificação do contexto cultural estranho às tradutoras e, por outro lado, elas realizaram a recontextualização dos contos em alemão atual e adequado, de modo a permitir a aproximação dos leitores alemães a esse contexto cultural estranho. Ou seja, o pré-requisito para uma tradução efetivamente mediadora, qual seja, o de que o tradutor seja bilíngue e bicultural, foi atendido aqui no trabalho em equipe.

Os critérios estabelecidos por nós para a escolha dos contos foram que, primeiramente, a autora deveria ter começado a publicar a partir dos anos 90, pois queríamos divulgar o que há de mais novo na literatura brasileira de autoria feminina; em segundo lugar, interessaram-nos contos que contivessem marcas culturais específicas de diversas regiões do Brasil, de modo a contemplar a diversidade cultural brasileira.

Consideramos que o público leitor alemão que se propõe a ler uma antologia de contos de um outro país, tenha interesse nesta outra cultura e disponha de uma atitude receptiva, de abertura em relação a elementos para ele estranhos. Por isso não quisemos naturalizar os textos, e sim, manter sua estranheza cultural, procurando realizar uma mediação que possibilitasse um acesso a essa 
estranheza. A intenção não era explicar tudo, mas ao mesmo tempo também não apagar os elementos estranhos, mesmo correndo o risco de colocar leitores diante de situações de uma compreensão apenas parcial ou até mesmo de não compreensão. Esta percepção parcial é comum no encontro entre culturas, bem como nas relações humanas em geral, até quando se trata de pessoas de um mesmo país, de uma mesma região ou localidade. Mas o importante para nós foi que se oferecesse ao público leitor a oportunidade de um encontro com a outra cultura, sendo que nos vimos como mediadoras nesse encontro.

\section{Questões de contexto em nossa tradução}

Mary Snell-Hornby distingue dois níveis de especificidade cultural na tradução de um texto literário: "In our concept translation begins with the text-in-situation as an integral part of the cultural background whereby text analysis proceeds from the macro-structure of the text to the micro-unit of the word." (1988: 2)

\section{O nível da macro-estrutura textual}

Defrontamo-nos, na tradução dos contos em questão, com problemas referentes ao contexto cultural no nível macro-textual, ou seja, o texto literário como um todo, como um enunciado específico, um determinado tema abordado de um modo culturalmente específico - estranho para leitores de outra cultura. Alguns exemplos:

O conto Ficção de Beatriz Bracher (in Ruffato, 2005) representa uma situação de violência urbana e luta de classes numa grande metrópole. A narradora-protagonista do conto, uma socióloga de classe média alta, fala, em linguagem muito elaborada, de sua difícil e polêmica decisão de comprar um carro blindado. Num se- 
gundo momento do conto ela encontra-se num engarrafamento e é abordada por um bandido armado, que exige que ela abra o vidro do carro. Ela não se assusta muito, pois se sente segura em seu blindado; apenas observa o ladrão esbravejando, até que, de repente, lembra que não está no carro blindado, pois é dia de rodízio. Sua feição de desespero faz o ladrão perceber o equívoco e quebrar o vidro imediatamente. Ele a esbofeteia no rosto e sai correndo, deixando em seu colo a arma de brinquedo. É uma dupla ficção, a da mulher, sentindo-se segura num carro que não é blindado, e a do ladrão assaltando com arma de brinquedo. $\mathrm{O}$ teor do enredo é culturalmente muito distante do público leitor alemão que não necessita de blindados no seu dia a dia.

No texto Mãe o cacete de Ivana Arruda Leite (in Ruffato, 2004) a protagonista, uma mulher de meia idade, descreve as desagradáveis lembranças que tem de sua mãe: alguém, por quem não nutre qualquer estima ou respeito, já que nunca recebeu dela a menor demonstração de afeto. Esta mãe não lhe ensinou as coisas mais elementares, deixando-a abandonada à própria sorte; importava-se apenas com a própria beleza e o seu amante. Frases como "o mundo seria outro sem mães. Deus que se virasse pra fazer as pessoas nascerem de outro jeito. Repolhos, bromélias. Os filhos seriam todos órfãos, órfãos e felizes" (p. 205), representam uma violenta quebra de tabu no Brasil, onde a figura da mãe costuma ser idolatrada; muito provavelmente o efeito não será o mesmo na Alemanha.

O conto mítico-alegórico Cântico da subida de Maria Valéria Rezende (in Ruffato, 2005), em que um muro intransponível é construído ao redor de um enorme morro onde imperam a pobreza e a miséria, alude a uma religiosidade de cunho social como a conhecemos no Brasil a partir da assim chamada Teologia da Libertação. Numa alusão ao Cristo, um menino pichador com uma lata de spray vermelho é seguido pela narradora, morro acima e pobreza adentro, até o alto do morro, onde ele a convida a participar da sua obra: "Quer pichar também, tia?, sobrou tinta, picha junto do meu risco, aqui, bem no começo do mundo" (p. 222). O conto como 
um todo, certamente, se constitui numa imagem estranha para a cultura alemã.

$\mathrm{O}$ erotismo ligado a elementos do sincretismo religioso tipicamente brasileiro no conto Eucaristia ${ }^{3}$, de Andréa del Fuego (in Fuego 2004: 80) também deverá causar estranhamento e uma certa incompreensão na cultura alemã, já que a sociedade alemã contemporânea é, de um modo geral, mais secularizada que a brasileira. O conto trata de uma quarentona de classe média baixa, mulher de motorista de ônibus, devota de São Jorge. Esta ajoelha-se diariamente diante de um altar em sua casa, chegando a passar horas diante dele e entrando em transe, o que deixa a família preocupada. À noite tem sonhos eróticos com o santo, o que lhe causa remorsos. Certa noite, como na lenda, São Jorge chega a cavalo e salva-a das garras ameaçadoras de um dragão; em seguida rende-se a ela numa união místico-erótica.

O conto Duzu Querença de Conceição Evaristo (in Alves / Lima, 2005) $)^{4}$ trata, com muita sensibilidade, da história de uma menina afro-brasileira que foge da pobreza no interior do Brasil para a cidade grande, onde, o que lhe aguarda, é o meretrício, e no final da vida, a mendicância. Também um pano de fundo cultural muito distante dos leitores alemães, certamente.

A solução por nós encontrada para mediar esta estranheza no nível macro-textual foi o emprego de paratextos. Um destes é uma biografia das autoras no final do livro, situando-as em termos geográficos e falando de suas atividades, o que em diversos casos pode representar uma chave para a compreensão de seu texto literário. Por exemplo: indicamos que Beatriz Bracher é paulistana; que Maria Valéria Rezende pertence a uma ordem religiosa e realiza trabalhos sociais no nordeste há muitos anos; que Andréa del Fuego é autora de literatura erótica; que Conceição Evaristo é escritora afro-brasileira.

Um outro paratexto é o prefácio da antologia, que oferece, em uma ou duas frases sobre cada história, uma espécie de sugestão de interpretação. Com relação a Mãe o cacete, por exemplo, o 
prefácio diz que o conto de Ivana Arruda Leite rompe com a imagem tipicamente brasileira da mãe como 'santa'. Sobre o conto de Andréa del Fuego o prefácio diz que se trata ali de um erotismo feminino que encontra um solo fértil exatamente na atmosfera místico-religiosa entre as camadas populares brasileiras.

Ainda outro paratexto é uma nota da tradutora no conto Eucaristia, que elucida um jogo intertextual com a lenda de São Jorge na história, conhecimento este fundamental para a compreensão do enredo como um todo. A lenda, muito conhecida no Brasil por se tratar de um dos santos mais populares de nossa cultura, é, muito provavelmente, desconhecida em grande parte da Alemanha. ${ }^{5}$

\section{O nível da micro-unidade do vocábulo}

Trata-se aqui do nível micro-textual. Por um lado há os vocábulos ou expressões, denominadas tradicionalmente como realia, e que se configuram como marcas culturais específicas dentro do texto. Por outro há também questões de estilo literário e de registro linguístico, as quais precisam ser trabalhadas no nível micro-textual e que contribuem significativamente para a construção do sentido dos textos como um todo, exatamente em termos de seu contexto cultural. Em nosso projeto tradutório defrontamo-nos com várias situações no nível micro-textual. Alguns exemplos seriam:

O termo "rodízio" no conto Ficção não tem tradução para o alemão, uma vez que não existe na Alemanha este dispositivo para combater o caos no trânsito e problemas de poluição, como é o caso em São Paulo. Optamos por deixar a própria palavra em português no texto, sem indicação de nota, para não interromper o fluxo da narrativa naquele lugar, já que se trata do clímax do conto e consideramos que a ideia básica pode ser compreendida mesmo sem se saber o que significa especificamente o termo: "Um frio monstruoso me sobe do estômago e pára meu coração. Hoje é dia de rodízio, eu não estou no blindado" (in Ruffato 2005: 30). O 
leitor pode entender que a personagem se dá conta de que está desprotegida, mesmo que sem saber exatamente por quê; ao final do texto colocamos, então, a nota explicativa, para complementar a informação, com a qual o leitor pode perceber um nível ainda mais profundo de ironia na situação.

Em todos os contos decidimos manter os nomes dos personagens. Estes têm, por exemplo, uma função especial em Entrevista ao vivo, de Luci Collin, (in Collin, 2004) conto que traça um retrato satírico-grotesco de uma socialite brasileira. Na entrevista lhe é perguntado qual seria a origem do seu nome. Em sua resposta ela explica que "lá em casa teve primeiro a Dirlene, mistura de Dirceu com Marlene, depois a Francilene, mistura de Francisco e Marlene, a Joselene (que a gente chama de Dindoca) e daí eu" (Collin, 2004: 92-93). Este trecho ajuda a caracterizar a personagem enquanto oriunda de um meio social tipicamente interiorano ou de um nível sócio-cultural baixo. Mantivemos o trecho com os mesmos nomes, acreditando que o público leitor alemão perceba a ironia da construção dos nomes.

Os nomes também são muito significativos no conto de Conceição Evaristo, a começar pelo nome da protagonista, Duzu, além dos de seus ancestrais, Alafaia, Kiliã, Bambene. Por se tratar de nomes de origem africana, o leitor brasileiro infere que se trata de descendentes de escravos. Como essa informação não fica garantida com a simples manutenção dos nomes, já que o leitor alemão poderá considerar os mesmos simplesmente brasileiros, houve a necessidade de inclusão de uma informação adicional na frase: "Rostos dos presentes se aproximavam. Faces dos ausentes retornavam. Vó Alafaia, Vô Kilian, Tia Bambene, seu pai, sua mãe, seus filhos e netos" (in Alves / Lima 2005: 96) Na tradução foi incluído, após Vô Kilian, „que ainda sabiam tantas histórias da África”.

Die Gesichter der Lebenden kamen näher, die Köpfe der Verstorbenen kehrten zuruck. Großmutter Alafaia, Großvater Kiliã, die noch so viele Geschichten aus Afrika kannt- 
en, Tante Bambene, ihr Vater und ihre Mutter, ihre Kinder und Enkel.

Também foram tratadas com especial atenção no conto Duzu Querença certas expressões que se configuram numa verdadeira prosa poética. Esse aspecto não foi identificado de imediato pela tradutora, porém é fundamental para reproduzir o olhar sensível e solidário lançado pela instância narradora sobre a personagem central, olhar esse que se constrói exatamente a partir dessa linguagem poética. Sem esse cuidado o texto teria adquirido um tom meio piegas, sentimental na tradução, que o desvalorizaria na cultura de chegada.

Um exemplo é a expressão que aparece nas frases "algumas vezes ia entrar-entrando. E foi no entrar-entrando que Duzu viu várias vezes homens dormindo em cima das mulheres" (in Alves / Lima 2005: 90). A expressão 'entrar-entrando' ainda se repete ao longo dos parágrafos seguintes, representando não só a entrada sem autorização prévia da menina nos quartos das prostitutas, mas sua gradual perda da inocência e iniciação no meretrício, no bordel onde foi deixada pelo seu pai com o propósito de trabalhar como empregada e com a promessa de poder ir à escola. Um pouco adiante o texto diz: "Duzu voltava sempre. Vinha num entrar-entrando cheio de medo, desejo e desespero" (in Alves / Lima 2005: 92). Na tradução, "immer wieder kehrte Duzu in dieses Zimmer zuruck. Sie trat einfach ein, voller Angst, Verlangen und Verzweiflung“, pôde ser reconstruída a aliteração, muito significativa aqui. Quanto à expressão 'entrar-entrando', não há como refazer esta mesma construção em alemão, optando a tradutora por "sie trat einfach ein"; a expressão adquiriu um nível de estranheza semelhante ao texto de partida a partir de sua insistente e idêntica repetição.

Outro trecho marcadamente poético se dá mais ao final do conto, quando Duzu já é uma mendiga velha e maltrapilha, meio louca, e está preparando uma fantasia para o carnaval. Indignada com a crítica de um companheiro mendigo sobre o fato de a sua fantasia 
não parecer de baiana, mas de fada, por estar enfeitada com estrelas, a narradora, sempre solidária com Duzu, revela a sua reação:

Quem disse que estrela era só para fadas? Estrela era para ela, Duzu. Estrela era para Tático, para Angélico. Estrela era para a menina Querença, moradia nova, bendito ayê, onde ancestrais e vitais sonhos haveriam de florescer e acontecer. (in Alves / Lima, 2005: 96)

Querença é a neta preferida de Duzu, que ela vê como a extensão de sua vida, aquela que realizará os seus sonhos. Tomamos muito cuidado na reconstrução poética deste trecho, mantendo, por exemplo, a anáfora, além da expressão africana, e a substituição de um adjetivo por uma frase inteira, com o intuito de explicitar mais o significado da mesma:

(...) woher er denn wisse, dass Sterne nur fur Feen da sind? Sterne seien fur sie, fur Duzu. Sterne seien fur Tático, fur Angélico. Sterne seien fur die kleine Querença, ayê, ihr neues Zuhause, gesegnet sei dieses Leben, wo alte und lebendige Träume erbluhen und wahr werden. [...Querença, ayê, sua nova moradia, bendita seja esta vida, onde...].

A questão do registro linguístico também foi tratada por nós com especial cuidado. Observamos quem são os personagens que falam, que grupo social eles representam de alguma forma, que região do país, que interesses políticos, sociais, culturais eles defendem, etc.

Para o discurso do machista do morro carioca do conto $\mathrm{Mi}$ nha Flor de Lívia Garcia-Roza (in Ruffato, 2004), foi necessária a opção por um registro específico de um trabalhador comum, de pouca instrução, não podendo ser o conto traduzido para o alemão num registro que seria comum a qualquer cidadão da Alemanha, 
indiferentemente de sexo, classe social, profissão, idade, etc. É um monólogo 'vigoroso' de um machista típico da periferia do Rio. Ele observa sua mulher que está se arrumando para sair sozinha, e manda-a trocar de roupa, pois considera que o seu vestido é indecente. Como a esposa não acata imediatamente a ordem recebida, ele vai se irritando mais e mais, passando a humilhá-la de todas as formas, com gritos, palavrões, tapas, ofensas à sua índole e à das mulheres de sua família. O conto culmina com uma relação sexual entre os dois, após a qual ele a convida para saírem juntos, agora sim com o tal vestido. No trecho a seguir evidencia-se a questão do registro, que pôde ser muito bem trabalhada na tradução:

\begin{abstract}
Responde pra mim: você acha que eu sou otário? Olhe bem pra minha cara e vê se eu sou um panaca. Tenho feições de corno? Aparência de veado? Perfil de trouxa? Pois saiba que você tem ao seu lado um macho da mais alta estirpe da zona da praia e da periferia! (in Ruffato 2004: 137-138)

Denkst du ich bin bescheuert? Schau mich gefälligst an und dann sag mir in die Fresse, ob du mich fur einen schwulen Waschlappen hältst. Willst du mich verarschen? Sehe ich etwa aus wie ein behinderter Depp? Meinst du ich bin ein Schlappschwanz? Du hast wohl immer noch nicht gerafft, dass du mit dem geilsten Hengst von ganz Rio zusammen bist!
\end{abstract}

Este trecho aponta também para outra questão culturalmente específica, e ao mesmo tempo própria para o registro em questão, que é a do vocabulário de xingamento. Otário, panaca, corno, veado, trouxa têm um rico vocabulário análogo em alemão, como, numa tradução aproximada, lesado, paninho higiênico abichalhado, fodido, débil mental, rabo brocha. Outro exemplo seria o seguinte trecho, em que o machista acusa a mulher de ser muito ativa sexualmente: "O que você pensa que é? Sou todo ouvidos, Heloísa. Você acha que é uma samambaia? Uma hortaliça? Uma esponja?"7 (in Ruffato 2004: 138) 
Was glaubst du eigentlich, wer du bist? Ich bin ganz Ohr, Heloísa. Hältst du dich fur eine Steckdose, ein Karnickel, fur ein Loch?

Os termos análogos em alemão aqui empregados, foram tomada, coelho, buraco. As metáforas são outras, porém a conotação é semelhante.

Já a fala da personagem em $O$ homem da casa, de Jeanette Roszas (in Roszas, 2005), teve de ser traduzida com um registro bem diferente daquele do conto Minha flor. Aqui ressoa a voz de um executivo, e seu discurso tem marcas de gênero muito claras. A surpresa é que 'o homem da casa' na verdade é uma mulher, o que o leitor só descobre no final do conto. O emprego de expressões de xingamento típicas do vocabulário masculino brasileiro, ajudam a reforçar tal engano. Dois trechos exemplificam a questão: "Nem bem piso o último degrau, vejo que esqueci a pasta com todo o material da reunião de hoje. (putamerda!)." (Roszas, 2005: 101)

Kaum dass ich die letzte Treppenstufe erreiche, bemerke ich, dass ich meine Aktentasche mit allen Unterlagen fur die heutige Besprechung vergessen habe. (Verdammte Schei$\beta e !)$

Chegamos na garagem, despeço-me do vizinho, que mal responde (até que ficou puto com razão, eu também ficaria). (Roszas, 2005: 101)

Wir betreten die Tiefgarage, ich verabschiede mich von meinem Nachbarn, der kaum antwortet (eigentlich ist er zu Recht stocksauer, ich wäre es auch an seiner Stelle).

Embora as expressões em questão também sejam utilizadas por mulheres no Brasil, elas soam muito mais naturais na voz do pretenso executivo da história, do que se o leitor soubesse que se trata de uma mulher. A tradutora comentou que no alemão não haveria essa diferenciação de emprego do vocabulário mencionado em ter- 
mos de gênero e ela também não conseguiu encontrar semelhante variedade de palavrões, mesmo após haver consultado falantes alemães do sexo masculino. A tarefa de construir a ilusão de um personagem masculino teve de ser realizada, pois, sem o auxílio que o vocabulário de xingamento constante no texto representa em português.

Em todos os casos comentados acima trata-se de questões de contexto. São conhecimentos subjacentes que as autoras dos textos de partida têm em comum com os seus leitores presumidos, ou seja, brasileiros em geral, ou em alguns casos também de uma determinada região brasileira apenas, e que não são automaticamente acessíveis a leitores de outras culturas. Daí a necessidade da recontextualização no processo de tradução. A experiência com a presente antologia mostrou não só que traduzir é envolver-se num intenso processo de mediação cultural, mas que essa tarefa pode ser especialmente prazerosa quando realizada por uma equipe de tradutores composta por ambas as culturas em questão.

\section{Notas}

1. Termo cunhado por Antoine Berman. (1995: 76)

2. Vale dizer que há apenas uma antologia de literatura de mulheres brasileiras, traduzida para o alemão, anterior a esta. Trata-se de uma antologia de contos eróticos de escritoras brasileiras: Mertin, Ray-Gude (Hrsg.) 'Tigerin und Leopard'. Erotische Erzählungen brasilianischer Autorinnen. ausgewählt von Márcia Denser und ubersetzt von Sarita Brandt. Zurich: Ammann, 1988.

3. Este conto, em português e na tradução para o alemão, juntamente com um artigo a respeito do processo tradutório, deverá ser publicado em breve na Revista Cadernos de Literatura em Tradução da USP. 
4. Este conto já foi traduzido e publicado na Inglaterra por Alves / Lima, conforme bibliografia acima.

5. É importante observar que as tradutoras vivem no lado oriental da Alemanha, que, devido aos quarenta anos de sistema comunista, sofreu um significativo processo de secularização. Já no sul da Alemanha, especialmente na Baviera, predomina ainda uma forte tradição católica, incluindo o culto a São Jorge.

6. Possivelmente nem mesmo todo leitor brasileiro saiba o que significa este termo.

7. É interessante observar que não se trata aqui de um vocabulário apenas específico em termos de classe social, mas que costuma ser regionalmente específico. No linguajar carioca, samambaia significa mulher que se esparrama, ou que dá em pé, hortaliça é a que dá no chão e esponja é a que absorve tudo. Também aqui é bem possível que nem todo leitor brasileiro entenderia essas expressões.

\section{Bibliografia}

ALVES, Miriam; LIMA, Maria Helena. (Eds.) (2005). Women Righting/ Mulheres Escre-Vendo: Afro-Brazilian Women's Short Fiction/Uma Antologia Bilingue de Escritoras Afro-Brasileiras Contemporâneas. (City Colours Series). London: Mango Publishing.

BASSNETT, Susan; LEFEVERE, André (Eds.). (1990). Translation, History and Culture. London and New York: Pinter Publishers.

BERMAN, Antoine. (1995). Pour une critique des traductions; John Donne. Paris: Gallimard.

COLLIN, Luci. (2004). Inescritos. Curitiba: Travessa dos Editores. 
FUEGO, Andréa del. (2004). Minto enquanto posso. São Paulo: O nome da Rosa.

HOUSE, Juliane. (2002). "Universality versus culture specificity in translation". In: RICCARDI, Alessandra (ed.) Translation Studies. Perspectives on an Emergin Discipline. NY: Cambridge University Press.

KATAN, David. (1999). “"What is it that's going on here?»: Mediating Cultural Frames in Translation”. In: BASSNETT, Susan; BOSINELLI, Rosa Maria Bolletieri; ULRYCH, Margherita (ed.). Translation Studies Revisited. Textus (English Studies in Italy) Vol XII n.2 (Juli-December).

ROSZAS, Jeanette. (2005). Qual é mesmo o caminho de Swan? Rio de Janeiro: 7 Letras.

RUFFATO, Luiz. (Org.) (2004). 25 Mulheres que estão fazendo a nova literatura brasileira. RJ/ SP: Record.

RUFFATO, Luiz. (Org.) (2005). + 30 mulheres que estão fazendo a nova literatura brasileira. RJ/SP: Record.

SNELL-HORNBY, Mary. (1988). Translation Studies: an Integrated Approach. Amsterdam and Philadelphia: John Benjamins.

TANQUEIRO, Helena. (2002). Autotradução, Autoridade, privilégio e modelo. (Diss.) UAB, Barcelona. Disponível em http://www.tdx.cat/TDX-1030103182232 acessado em 03.09.2008. 
